\title{
ВОЗМОЖНОСТИ ИСПОЛЬЗОВАНИЯ ИНФОРМАЦИОННЫХ ТЕХНОЛОГИЙ В СИСТЕМЕ ДОСТАВКИ ГРУЗОВ
}

\section{POSSIBILITIES OF USING INFORMATION TECHNOLOGIES IN THE CARGO DELIVERY SYSTEM}

\section{A. Lipatov}

Summary: The article deals with modern information systems for automating the process of cargo delivery. An analysis of their integration into modern logistics infrastructure is given, and technologies that complement this process are studied. The paper concludes that the pandemic has created new requirements and boundaries for the platforms used, allowing them to integrate into the company's overall software system. The choice of information technology in automating the process of cargo delivery management is individual for each company and should take into account its size, orientation, number of business processes, and level of logistics development.

Keywords: logistics, automation, cargo, delivery, technology, digitalization.
Липатов Андрей Геннадьевич

К.э.н., доцент, Государственный университет управления tr172@mail.ru

Аннотация: В статье рассматриваются современные информационные системы автоматизации управления процессом доставки грузов. Приводится изучение возможностей интеграции их в современную логистическую инфраструктуру, изучаются технологии, дополняющие данный процесс. В работе сделан вывод, что выбор информационной технологии в автоматизации процесса управления доставкой грузов является индивидуальным для каждой компании и должен учитывать ее размеры, направленность, число бизнес-процессов, уровень развития логистики.

Ключевые слова: логистика, автоматизация, грузы, доставка, технологии, цифровизация.

Поэтому при помощи информационных технологий, которые разработаны в современных условиях, появляются возможности формирования наиболее модернизированной единой системы управления логистикой, подпроцессом которой является доставка или транспортировка продукции до склада поставщика (собственного склада хранения). Это позволит в последствии значительно ускорить процесс доставки и снизить потери, которые происходили во время транспортировки грузов, а также уменьшить себестоимость продукции [3].

Для выявления наиболее эффективных информационных систем, позволяющих автоматизировать процесс управления доставкой грузов, далее рассмотрим имеющиеся тенденции в отрасли, которые на сегодняшний день получили наибольшее распространение в России среди крупных логистических центров или компаний, имеющих широкую сеть комплексов и точек продаж [4]. При этом стоит пояснить, что большая часть автоматизированных средств позволяет формировать модель управления грузами по схеме, приведенной на рисунке 1.

Исследование концепций управления логистической системой позволило определить, что наиболее эффективными среди информационных систем являются основанные на системно-динамическом моделировании. Для анализа рынка автором проведён обзор программного 


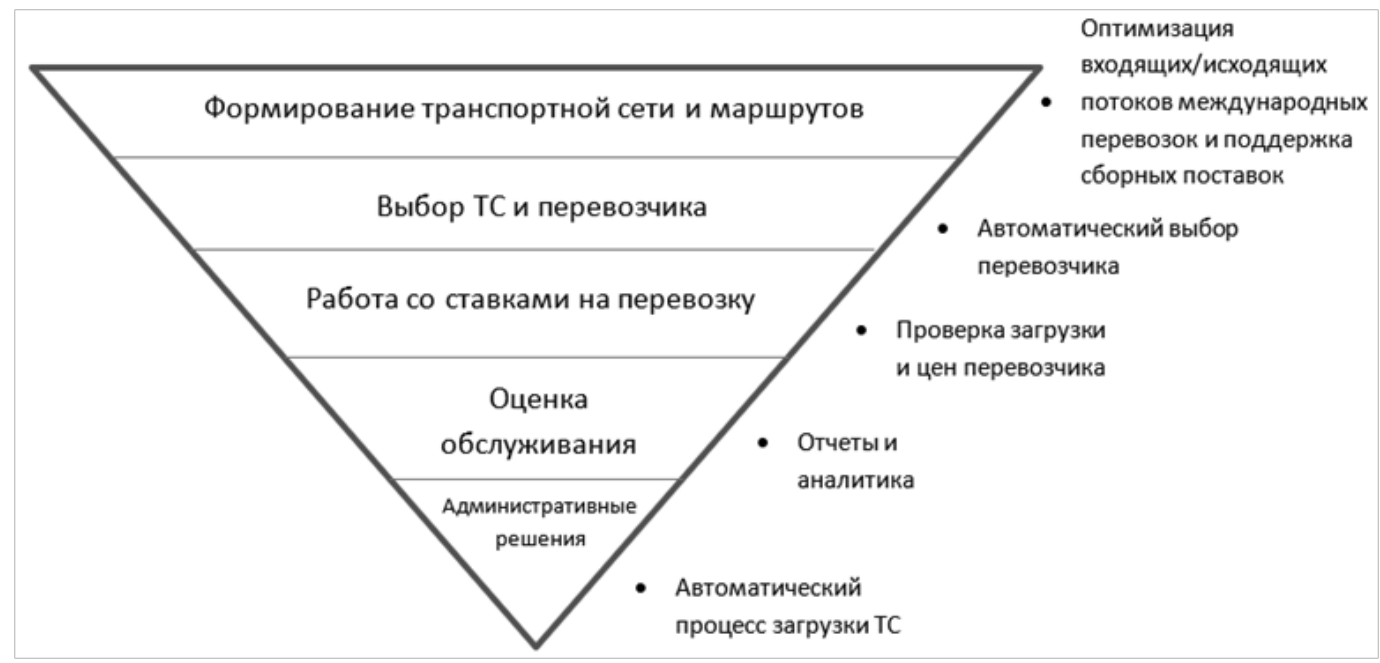

Рис. 1. Модель работы информационной системы по управлению доставкой грузов Источник: составлено автором по [6]

обеспечения, реализующего функции системно-динамического моделирования в логистике.

Проанализированы следующие виды программного обеспечения [8]:

1. MATLAB;

2. Simulink;

3. MATHCAD;

4. AnyLogic.

В таблице 1 приводится характеристика основных параметров выбранного ПО, включая возможности по обеспеченности принятия решений при управлении логистической системой.

Изучив возможности программных средств моделирования динамических систем, которые используются при формировании автоматизированных модулей управления перевозками грузов, выбор был сделан в пользу инструмента имитационного моделирования «AnyLogic».

В последнее обновление «Anylogic 8.1» была встроена новая библиотека моделирования материальных и финансовых потоков, открывающая новые возможности для использования в логистике.

Новая библиотека позволяет моделировать потоки транспорта и движения грузов среди складских помещений, а также имитировать физическое перемещение потоков от поставщика к покупателю, учитывая всех участников логистической сети: транспортные компании, организации хранения, сбытые предприятия. Появился инструмент визуализации плотности загрузки транспортных единиц, складских площадей, занятых в процессах перемещения грузов.
Основные элементы процесса управления логистической системой «AnyLogic» в части бизнес-процесса «перевозки грузов» систематизированы в таблице 2.

Таким образом, на основании системно-динамического моделирования в программе AnyLogic, возможно составить модель, способствующую оптимизации процесса доставки грузов, учитывающую показатели ключевой эффективности организаций (KPI). Здесь стоит подчеркнуть, что в программу могут быть интегрированы любые КРІ, свойственные логистической системе. Для управления перевозками грузов в качестве КPI могут быть выделены следующие показатели [7]:

- затраты на перевозку грузов;

- складские затраты;

- затраты на погрузку-разгрузку грузов;

- модели управления перевозкой грузов;

- виды транспорта, занятого перевозкой грузов;

- структура канала доставки;

- наличие логистических посредников;

— численность персонала, занятого в доставке;

- тип перевозки грузов.

Каждый из представленных показателей находится в зависимости от разных факторов. Накопителями в данной модели будут выступать показатели ключевой эффективности, а потоками - переменные, используемые для расчетов КPI [5].

Так, например «накопитель» затраты на перевозку грузов- зависим от переменных «структура канала доставки», «численность персонала, занятого в доставке», «тип перевозки грузов». В свою очередь функция, решаемая при помощи накопителя, влияет на показатель сопоставимости доходов и расходов от перевозки грузов. В таблице 3 содержится информация о накопителях и переменных каждого приведенного выше ключевого 
Таблица 1.

Характеристика параметров программного обеспечения, применяемого в построении автоматизированных систем управления логистическими системами предприятий

\begin{tabular}{|c|c|c|c|c|c|}
\hline П० & 0бщая характеристика & $\begin{array}{c}\text { Возможности } \\
\text { оптимизации потоков } \\
\text { процессов и логистики }\end{array}$ & $\begin{array}{l}\text { Надстройки логистиче- } \\
\text { ского управления }\end{array}$ & Преимущества & Недостатки \\
\hline MATLAB & $\begin{array}{l}\text { Пакет прикладных } \\
\text { программ для решения } \\
\text { задач экономических и } \\
\text { технических вычис- } \\
\text { лений }\end{array}$ & $\begin{array}{l}\text { В модели используется } \\
\text { результат работы } \\
\text { этих функций MATLAB } \\
\text { для динамического } \\
\text { изменения задержек } \\
\text { обработки, приорите- } \\
\text { тов и других ключевых } \\
\text { элементов процесса. }\end{array}$ & $\begin{array}{l}\text { Logistics Simulation } \\
\text { Software for Mission } \\
\text { Planning }\end{array}$ & $\begin{array}{l}\text { Понимание альтерна- } \\
\text { тивных вариантов и } \\
\text { компромиссов; } \\
\text { возможность раннего } \\
\text { выявления ошибок по } \\
\text { оптимизации логисти- } \\
\text { ческой системы; } \\
\text { позволяет контролиро- } \\
\text { вать точность каждого } \\
\text { компонента интерак- } \\
\text { тивно }\end{array}$ & $\begin{array}{l}\text { Отсутствие русскоязыч- } \\
\text { ных разработок; } \\
\text { Высокая стоимость } \\
\text { программного про- } \\
\text { дукта } \\
\text { Сложность интерфейса } \\
\text { и настроек }\end{array}$ \\
\hline Simulink & $\begin{array}{l}\text { Интерактивный } \\
\text { инструмент для моде- } \\
\text { лирования, имитации и } \\
\text { анализа динамических } \\
\text { систем }\end{array}$ & $\begin{array}{l}\text { Позволяет строить } \\
\text { графические блок- } \\
\text { диаграммы, дина- } \\
\text { мические системы, } \\
\text { анализировать работо- } \\
\text { способность систем }\end{array}$ & $\begin{array}{l}\text { Возможно исполь- } \\
\text { зовать надстройки } \\
\text { MATLAB }\end{array}$ & $\begin{array}{l}\text { Обеспечивает быстрый } \\
\text { доступ к широко- } \\
\text { му спектру методов } \\
\text { анализа и проектиро- } \\
\text { вания. Интегрируется с } \\
\text { с другими По. }\end{array}$ & $\begin{array}{l}\text { Сложность моделиро- } \\
\text { вания в программе; } \\
\text { необходимость допол- } \\
\text { нительных надстроек } \\
\text { для адаптации модели } \\
\text { к логистической } \\
\text { системе }\end{array}$ \\
\hline MATH-CAD & $\begin{array}{l}\text { Математический ре- } \\
\text { дактор, позволяющий } \\
\text { проводить техниче- } \\
\text { ские и инженерные } \\
\text { расчеты, возможно } \\
\text { адаптировать к моде- } \\
\text { лированию сложных } \\
\text { реализаций численных } \\
\text { методов }\end{array}$ & $\begin{array}{l}\text { Простота настройки, } \\
\text { наглядность матема- } \\
\text { тических действий, } \\
\text { широкая библиотека } \\
\text { функций и численных } \\
\text { методов, символьных } \\
\text { вычислений, аппарат } \\
\text { представления резуль- } \\
\text { татов. }\end{array}$ & $\begin{array}{l}\text { Delphi, (перечень } \\
\text { команд сервера } \\
\text { ограничен) }\end{array}$ & $\begin{array}{l}\text { Отсутствие возмож- } \\
\text { ностей разработки } \\
\text { графических интерфей- } \\
\text { сов пользователя }\end{array}$ & $\begin{array}{l}\text { Одни и те же контуры } \\
\text { выделяются иногда } \\
\text { несколько раз, что } \\
\text { усложняет адаптацию } \\
\text { их к разрабатываемой } \\
\text { модели }\end{array}$ \\
\hline AnyLogic & $\begin{array}{l}\text { Программное обеспе- } \\
\text { чение имитационного } \\
\text { моделирования нового } \\
\text { поколения }\end{array}$ & $\begin{array}{l}\text { Существенно упрощает } \\
\text { разработку моделей и } \\
\text { их анализ. }\end{array}$ & $\begin{array}{l}\text { Возможно использо- } \\
\text { вать надстройки }\end{array}$ & $\begin{array}{l}\text { Пакет поддерживает } \\
\text { все методы имитаци- } \\
\text { онного моделирова- } \\
\text { ния: } \\
\text { моделирование дина- } \\
\text { мических систем; } \\
\text { дискретно-событийное } \\
\text { моделирование; } \\
\text { системная динамика; } \\
\text { агентное моделиро- } \\
\text { вание. }\end{array}$ & $\begin{array}{l}\text { Сложность адаптации } \\
\text { модели к процессно- } \\
\text { ориентированному, } \\
\text { системно-динами- } \\
\text { ческому и агентному } \\
\text { подходам }\end{array}$ \\
\hline
\end{tabular}

Источник: составлено автором самостоятельно

показателя эффективности.

Исходя из того, что ряд накопителей имеет схожие переменные и одинаковые функции, появляется возможность объединения накопителей по принципу схожести выполняемых ими функции. В частности это:

- сбытовые затраты;
- складские затраты;

- модели управления запасами;

- тип логистических посредников.

Занесение представленных накопителей с приведенными в таблице 3, сопровождающими их переменными, позволит компании разработать модель поддержки 
Таблица 2.

Элементы архитектуры «AnyLogic» в части бизнес-процесса «перевозки грузов»

\begin{tabular}{|c|c|}
\hline Задача & Описание \\
\hline $\begin{array}{l}\text { Блок «Производство». Управление запасами и } \\
\text { организацией производства }\end{array}$ & $\begin{array}{l}\text { Стратегические и оперативные планы формирования цепочек поставок запасов; } \\
\text { Разработка процесса принятия решений по организации поставок; } \\
\text { Поиск методов оптимизации перемещения запасов; } \\
\text { Снижение товарных потерь }\end{array}$ \\
\hline Блок «Финансы»: Склад, снабжение, сбыт. & $\begin{array}{l}\text { Стратегический план распределения финансовых ресурсов между бизнес-процессами; } \\
\text { Оптимизация сбытовых затрат; } \\
\text { Оптимизация расходов на перемещение товаров; } \\
\text { Повышение точности и достоверности плановых расчётов }\end{array}$ \\
\hline $\begin{array}{l}\text { Блок «Бизнес-процессы»: разработка модели биз- } \\
\text { нес-процессов, учитывающей ключевые показатели } \\
\text { эффективности }\end{array}$ & $\begin{array}{l}\text { Оптимизация сбытовой сети и каналов распределения товаров } \\
\text { Сокращение звеньев в канале распределения путем отказа услуг от ненужных посредников } \\
\text { Отказ от части посредников, участвующих в сбытовой сети }\end{array}$ \\
\hline
\end{tabular}

Источник: составлено автором самостоятельно

Таблица 3

Информация для формирования системно-динамической модели поддержки принятия решений при управлении логистической системой

\begin{tabular}{|c|c|c|c|}
\hline Накопитель модели & Переменные & $\begin{array}{l}\text { Функция, решаемая при помощи } \\
\text { накопителя }\end{array}$ & Влияние функции \\
\hline затраты на перевозку грузов & $\begin{array}{l}\text { «структура канала доставки», } \\
\text { «численность персонала, занятого в } \\
\text { доставке», «тип перевозки грузов» }\end{array}$ & $\begin{array}{l}\text { формирование оптимального кана- } \\
\text { ла перевозку грузов, минимизация } \\
\text { затрат }\end{array}$ & сопоставимость доходов и расходов \\
\hline складские затраты & $\begin{array}{l}\text { «склад», «объем грузопотока», } \\
\text { «время хранения», «товарные } \\
\text { потери» }\end{array}$ & $\begin{array}{l}\text { распределение остатков товаров на } \\
\text { складе, повышение оборачиваемо- } \\
\text { сти товаров, снижение расходов на } \\
\text { хранение }\end{array}$ & $\begin{array}{l}\text { снижение товарных потерь, рост } \\
\text { объема продаж, увеличение при- } \\
\text { были }\end{array}$ \\
\hline $\begin{array}{l}\text { модели управления перевозкой } \\
\text { грузов }\end{array}$ & $\begin{array}{l}\text { «склад» «перевозки грузов», «объем } \\
\text { грузооборота», «потери во время } \\
\text { перевозки грузов» }\end{array}$ & $\begin{array}{l}\text { ускорение времени перевозки гру- } \\
\text { зов, снижение расходов на хранение }\end{array}$ & $\begin{array}{l}\text { формирование эффективной логи- } \\
\text { стической системы }\end{array}$ \\
\hline $\begin{array}{l}\text { виды транспорта, занятого перевоз- } \\
\text { кой грузов }\end{array}$ & $\begin{array}{l}\text { «объем грузооборота», «потери во } \\
\text { время перевозки грузов», «рас- } \\
\text { ходы на транспорт», «расходы на } \\
\text { хранение» }\end{array}$ & $\begin{array}{l}\text { снижение расходов на перевозку } \\
\text { грузов, формирование оптимально- } \\
\text { го маршрута доставки грузов }\end{array}$ & $\begin{array}{l}\text { сопоставимость расходов на транс- } \\
\text { порт }\end{array}$ \\
\hline тип логистических посредников & $\begin{array}{l}\text { «0бъем продаж», «сбыт продукции», } \\
\text { «дефицит продукции» }\end{array}$ & $\begin{array}{l}\text { снижение расходов на перевозку } \\
\text { грузов, формирование оптимально- } \\
\text { го размера запасов }\end{array}$ & $\begin{array}{l}\text { сопоставимость объемов грузообо- } \\
\text { рота и расходов на доставку грузов }\end{array}$ \\
\hline
\end{tabular}

Источник: составлено автором самостоятельно

принятия решений при управлении логистической системой, учитывая ее особенности.

Формирование индивидуальной модели управления перевозками грузов в системе «AnyLogic» позволит своевременно выявлять факторы, негативно сказывающиеся на финансовых результатах компании. Таковыми могут быть:

1. низкий уровень складских расходов, оказывающий влияние на рост товарных потерь и снижение качества, и скорость перевозки грузов;

2. наличие сбоев в поставках, что влечет товарные потери и снижение конкурентоспособности предприятия;

3. недостаточный грузооборот, неэффективная карта маршрутов распределения грузов.

На основании выявленных факторов далее разрабатывается набор управленческих решений, способствующих повышению эффективности логистической системы и, в частности, процесса перевозки грузов. Такими могут быть следующие управленческие решения:

1. реорганизация отдела логистики, что позволит устранить все выявленные недостатки системы 
доставки грузов;

2. формирование новой системы хранения товаров;

3. разработка новой методики формирования карт маршрутов транспорта;

4. выделение отдельного специалиста, руководящего перевозками грузов компании.

Разработка управленческих решений должна сопровождаться определением рисков и показателей эффективности функционирования логистической системы.
Не стоит забывать, что рассмотренные системы постоянно совершенствуются. При этом пандемия стала важным триггером, способствующим цифровой трансформации в доставки грузов вместе с общим сдвигом транспортно-логистической системы в онлайн. Современные онлайн-решения позволяют управлять рисками грузоперевозок, снижая при этом не только в разы административные издержки, но и в отдельных случаях принося ощутимый экономический эффект.

\section{ЛИТЕРАТУРА}

1. Антоненкова А.В., Шайтура С.В., Анализ информационных систем в логистике / Транспортное дело России, 2015. № 5. С. 105-106.

2. Веремеенко Е.Г. Проблемы и перспективы российского рынка транспортно-логистических услуг // Молодой исследователь Дона - 2018 - № 4 Дыбская В.В. [и др.]; под ред. Сергеева В.И. Логистика. - М.: Эксмо, 2013. - 944 с. — (Полный курс МВА).

3. Косюга 0.С., Коляда В.В. Применение архитектуры клиент-сервер и файл-сервер в информационных системах. В сборнике: Информационное общество: современное состояние и перспективы развития Сборник материалов XI международного студенческого форума. 2018. С. $52-55$.

4. Рыбальченко, М.В. Архитектура информационных систем: учеб.пособие для вузов / М.В. Рыбальченко. — Москва: Издательство Юрайт, 2016. — 91 с

5. Дмитрук, К.А. Информационно-логистические системы / К.А. Дмитрук. — Текст : непосредственный // Молодой ученый. — 2020. — № 19 (309). — C. 17-21. — URL: https://moluch.ru/archive/309/69745/ (дата обращения: 25.11.2020).

6. Логистические информационные системы: http://logistic-info.ru/informacionnye-sistemy.html(дата обращения: 25.11.2020).

7. Тенденции рынка информационных систем управления транспортной логистикой// https://www.tadviser.ru/index.php (дата 0бращения: 25.11.2020).

8. Применение IT-технологий в транспорте и логистике. Серверное и сетевое оборудование для транспортных и логистических компаний // https://www.karma-group.ru/transport_logistic/(дата обращения: 25.11.2020).

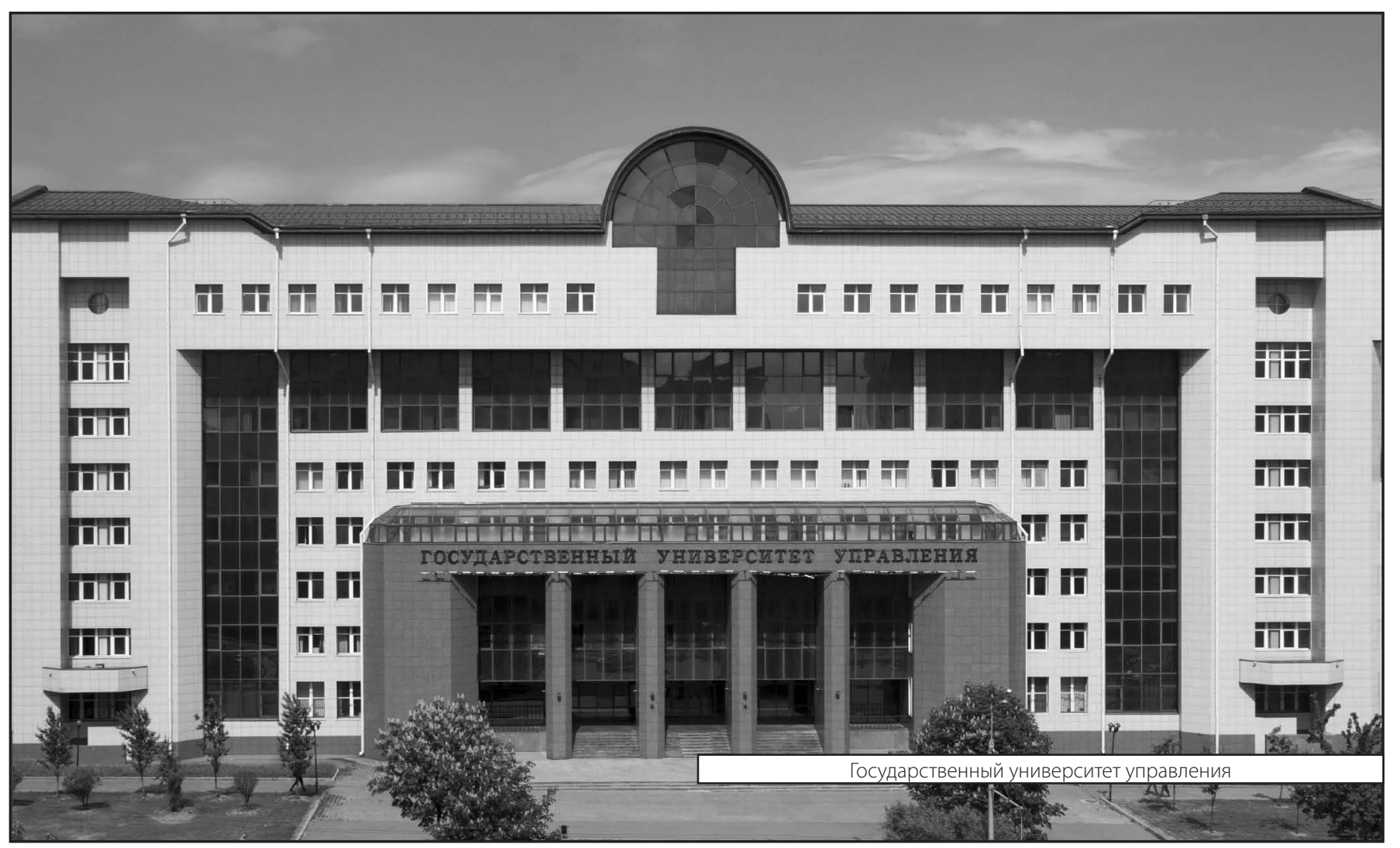

